\title{
Impact of Comorbidity on Length of Stay of Hospitalized Pneumonia in Children
}

\author{
Nur Mala Il A'la, ${ }^{1}$ Adi Utomo Suardi, ${ }^{2}$ Dewi Kartika Turbawati ${ }^{3}$ \\ ${ }^{1}$ Faculty of Medicine Universitas Padjadjaran, ${ }^{2}$ Department of Child Health Faculty of Medicine \\ Universitas Padjadjaran/Dr. Hasan Sadikin General Hospital Bandung, ${ }^{3}$ Department of Clinical \\ Pathology Faculty of Medicine, Universitas Padjadjaran/Dr. Hasan Sadikin General Hospital \\ Bandung
}

\begin{abstract}
Background: The incidence of pneumonia in children under-five in West Java is high. The average length of stay (LOS) often exceeds the standards set by the Indonesia-Disease Related Group (INA-DRG) because of the comorbidities. It can cause financial loss for the hospital. This study was conducted to analyze the impact of comorbidity on LOS.

Methods: Data was collected from medical records of 296 hospitalized pneumonia under-five children in the Department of Child Health Dr. Hasan Sadikin General Hospital Bandung in the period from JanuaryDecember 2012 that consisted of patient's identity, LOS, primary diagnosis, and comorbid diagnosis. Data was selected through inclusion and exclusion criteria and statistically analyzed using the chi-square and Spearman correlation test.

Results: Out of 218 subjects, those who had major comorbidities and minor comorbidities was 79 (36.2\%) and $39(17.9 \%)$, respectively. The average LOS of those who had major and minor comorbidities was $8.33 \pm 8.252$ days and $5.95 \pm 3.554$ days, respectively. Congenital heart disease had the highest and most

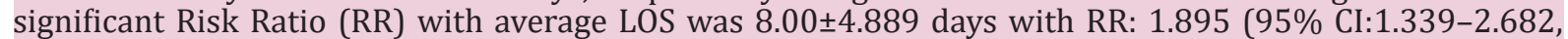
$\mathrm{p}=0.001)$.

Conclusions: Subjects have higher average LOS than the LOS set by the INA-DRG. Congenital heart disease is the most common comorbidity and has the highest and the most significant risk ratio. [AM].2017;4(1):42$6]$
\end{abstract}

Keywords: Comorbidity, Indonesia-Disease Related Group (INA-DRG), length of stay (LOS), pneumonia, under-five children

\section{Introduction}

According to the Indonesia Demographic Health Survey, the incidence of pneumonia in children under-five in West Java in 2009 was entered into the category of red or high $(>4 \%) .{ }^{1}$ Currently, in the implementation of health services with the financing program of Jaminan Kesehatan Masyarakat (Jamkesmas) and Keluarga Miskin Daerah (Gakinda) from the government, Dr. Hasan Sadikin General Hospital (RSHS) Bandung has sought the implementation of the casemix system with the Indonesia-Disease Related Group (INA-DRG). The INA-DRG is a health care classification system into a certain amount of financing based on diagnosis that consists of health care package rates including diagnosis, length of stay (LOS), and the cost per diagnosis of disease. ${ }^{2}$

The real LOS that occurred in the hospital can be greater than the INA-DRG standard and one of the reasons is the presence of the secondary diagnoses or comorbidities. If the real aLOS of a hospital exceeds the standard of INA-DRG, it may lead to higher costs that should be incurred. If this happens continuously, it is assured that the hospital would lose more. ${ }^{3}$ Therefore, based on the above data, this study was conducted to analyze the impact of comorbidity toward the LOS of under-five year pneumonia patients of Jamkesmas or Gakinda participants in the Inpatient room of the Department of Child Health RSHS Bandung in the period from January-December 2012.

Correspondence: Nur Mala Il A'la, Faculty of Medicine, Universitas Padjadjaran, Jalan Raya Bandung-Sumedang Km.21, Jatinangor, Sumedang, Indonesia, Phone: +62 8978311516 Email: mala.1612@gmail.com 
Table 1 Comorbidity and Length of Stay (LOS)

\begin{tabular}{lccccc}
\hline & \multicolumn{5}{c}{ Length of Stay ( days ) } \\
\cline { 2 - 6 } & Min* & Max* & Mean & SD & INA-DRG \\
\hline Without comorbidity & 1 & 20 & 5.27 & 3.446 & 5.5 \\
Minor comorbidity & 1 & 20 & 5.95 & 3.554 & 5.6 \\
Major comorbidity & 1 & 71 & 8.33 & 8.252 & 7.8 \\
\hline
\end{tabular}

Note ${ }^{*}$ Min $=$ minimum, $\max =$ maximum

\section{Methods}

This study was an analytic study with a crosssectional design, conducted from OctoberNovember 2013. Data was obtained with total sampling from 296 medical records of the under-five hospitalized pneumonia Jamkesmas or Gakinda patients of the Department of Child Health, Dr. Hasan Sadikin General Hospital Bandung in the period from JanuaryDecember 2012. This study was approved by the Health Research Ethics Committee Faculty of Medicine Universitas Padjadjaran.

The inclusion criteria were pneumonia patients hospitalized in the pediatric ward in the period from January-December 2012, who were participants of Jamkesmas or Gakinda, aged between 2 months to 5 years, and were discharged with approval. The exclusion criteria of the study subjects were patients who died during hospitalization. Furthermore, comorbidities of pneumonia are anemia, quadriplegia, diarrhea, malnutrition, and congenital heart disease. The severity of pneumonia is classified as severe pneumonia and very severe pneumonia. Patients were diagnosed clinically if they had cough or were breathing rapidly. If the child has a lower chest wall indrawing or stridor, the child is diagnosed with severe pneumonia. If the state is added with cyanosis, cannot drink or breast-feed, or there is a change in conciousness, the child is diagnosed with very severe pneumonia.4 The LOS amounted from the admission of the patient until the discharge of the patient.

Data were statistically analyzed using the chi-square test for the comparative test and the Spearman correlation test to assess the correlation between the variables. It was considered statistically significant when $\mathrm{p} \leq 0.05$ level.

\section{Results}

The number of hospitalized pneumonia underfive children in the Child Health Department of RSHS Bandung in the period from JanuaryDecember 2012 amounted to 375 people, but the data that could be retrieved in this study was only of 296 people. Out of 218

Table 2 Comorbidities that Encompass Anemia, Quadriplegia, Diarrhea, and Malnutrition and Length of Stay (LOS)

\begin{tabular}{lcccccc}
\hline & Number & \multicolumn{5}{c}{ Length of Stay (days) } \\
\cline { 3 - 7 } & $(\mathbf{n})$ & Min* $^{*}$ & Max $^{*}$ & Mean & SD & INA-DRG \\
\hline Anemia & & & & & & \\
$\quad$ Underlying & 34 & 1 & 16 & 6.59 & 3.491 & 7.8 \\
$\quad$ Fe Deficiency & 39 & 1 & 23 & 7.18 & 5.281 & 5.6 \\
Quadriplegia & 26 & 3 & 71 & 9.19 & 13.026 & 7.8 \\
Diarrhea & 32 & 1 & 13 & 6.22 & 3.098 & 5.5 \\
Malnutrition & & & & & & \\
$\quad$ Severe & 16 & 3 & 71 & 12.94 & 16.234 & 7.8 \\
$\quad$ Mild-moderate & 21 & 1 & 17 & 6.76 & 3.961 & 5.6 \\
$\quad$ Congenital heart disease & 40 & 1 & 23 & 8.00 & 4.889 & 5.5 \\
\hline Note; * Min = minimum, max = maximum & & & & & &
\end{tabular}


Table 3 Comorbidity and Risk Ratio of Increasing Length of Stay (LOS)

\begin{tabular}{lcc}
\hline & $\begin{array}{c}\text { RR increasing length of stay } \\
\mathbf{( 9 5 \%} \mathbf{~ C I})\end{array}$ & $\mathbf{p}$ \\
\hline Anemia & $0.972(0.644-1.467)$ & 0.892 \\
Quadriplegia & $0.728(0.376-1.408)$ & 0.315 \\
Diarrhea & $1.215(0,785-1.880)$ & 0.403 \\
Malnutrition & $1.485(0.984-2.242)$ & 0.078 \\
Congenital heart disease & $1.895(1.339-2.682)$ & 0.001 \\
\hline
\end{tabular}

Table 4 Comorbidity and Its Correlation with Increasing Length of Stay (LOS)

\begin{tabular}{lccc}
\hline & LOS (days) & $\mathbf{r}$ & p (1-tailed) \\
\hline Anemia & 6.90 & -.009 & 0.446 \\
Quadriplegia & 9.19 & -.068 & 0.318 \\
Diarrhea & 6.22 & 0.057 & 0.203 \\
Malnutrition & 9.43 & 0.119 & 0.039 \\
Congenital heart disease & 8.00 & 0.220 & 0.001 \\
\hline
\end{tabular}

patients who met the inclusion and exclusion criteria, were 100 patients $(45.9 \%)$ with no comorbidity, 39 patients $(17.9 \%)$ with minor comorbidities, and 79 patients $(36.2 \%)$ with major comorbidity.

This study showed that minor and major comorbidity had an average LOS that exceeded the INA-DRG standard (Table 1).

In this study, the most common comorbidities were congenital heart disease. Patients with anemia due to Fe deficiency, quadriplegia, diarrhea, severe and mildmoderate malnutrition, as well as congenital heart disease had an average LOS that exceeded the INA-DRG standard. Patients with severe malnutrition had a higher average length of stay compared to most of the other comorbidities (Table 2).

This study also showed that congenital heart disease had a very significant risk ratio (RR) to increase the LOS (Table 3).

Overall malnutrition and congenital heart disease also had a significant correlation with the LOS (Table 4).

\section{Discussions}

This study found that the average LOS was higher than that set by the INA-DRG. One of the reasons is the presence of the secondary diagnoses or comorbidity. ${ }^{3}$

This study was also in line with the result of the study conducted by Pichard et al. ${ }^{5}$ which showed that the length of hospital stay for severely malnourished patients is significantly greater $(10.8 \pm 26.3$ days $)$ than the LOS for moderately malnourished patients $(5.4 \pm 8.2$ days) or well-nourished patients $(3.9 \pm 7.8$ days), this study also showed that patients with malnutrition have a higher average LOS $(11,320 \pm 9: 32),(p<0.05)$. These results indicate that malnutrition has an influence on the increase in the LOS in pneumonia patients. ${ }^{5}$ This is caused by malnutrition impaires immune function. ${ }^{6-9}$ This affects the speed of the patient to recover thus affecting the LOS.

This study was also in line with a study conducted by Sadoh et al. ${ }^{10}$ in 2013 which showed that children with congenital heart disease have a higher average LOS $(11.50 \pm 7.03)$ than patients without congenital heart disease $(7.38 \pm 5.34, p=0.012)$. This study also suggested that congenital heart disease had a higher average number of days of hospitalization $(8.00 \pm 4.889)$ and increased the LOS with RR: 1,895 (95\% CI:1.339-2.682, $\mathrm{p}=0.001$ ). Additionally, a congenital heart disease may cause a disturbance in Sterling forces. Increased hydrostatic pressure in the pulmonary capillaries increased driving pressure of the fluid to move out of the capillary. This pressure also damages the integrity of the alveolar-capillary membrane, causing capillary stress fracture. This causes the water to 
accumulate in the interstitial and alveoli which may become the source of lower respiratory tract infections. Water that accumulates in the alveoli interstitium can also cause hypoxia due to alveolar collapse, decreased functional residual capacity, and ventilation/perfusion mismatching, thus increasing the work of breathing to maintain adequate ventilation. This will cause tachypnea in patients whose symptoms are also symptoms of pneumonia. This will extend the length of stay. ${ }^{11,12}$

Other comorbidities such as anemia, quadriplegia, and diarrhea did not show RR and significant correlation toward the LOS .

Moschovis et al. ${ }^{13}$ stated that anemia as a comorbidity itself does not increase the risk of treatment failure. This is consistent with the study that the researcher conducted, that anemia did not have a significant RR to increase the LOS, although the data showed that patients with pneumonia and anemia due to Fe deficiency had a higher average LOS than that set by the INA-DRG.

In the literature review conducted by Krigger $^{14}$ patients with quadriplegia, for example caused by cerebral palsy, usually have oral malfunction so often associated with aspiration pneumonia due to the esophagus reflux. The collected data showed that patients with quadriplegia had longer average LOS than that specified in the INA-DRG, but quadriplegia did not have a significant RR to increase the LOS.

Walker et al..$^{15}$ showed that diarrhea and ALRI have a small positive correlation and occurred together more than chance alone $(0.15,95 \%$ CI:0.13-0.17). In this study, out of 32 patients suffering from diarrhea, 6 of them had acute dysentry diarrhea, and the rest had non-dysentery, while out of 300 patients, only 12 were cultured and showed positive results. The microorganisms found in the culture results to find the cause of pneumonia in patients included Acinetobacter iwofii, Burkholderia cepacia, Klebsiella pneumoniae, Haemophilus influenza type $B$, Pseudomonas aeruginosa, Serratia marcescens, Staphylococcus hominis, and Streptococcus pneumoniae, with Staphylococcus hominis which became microorganism that were most frequently found. However, all of the patients who were positive on culture, showed no incidence of diarrhea at all. The main cause was the small number of this culture, while the number of negative culture results might be caused by taking antibiotics prior to culture or was suffering from pneumonia caused by viruses that couldnot grow in culture.
Diarrhea in patients also may be caused by nosocomial infection. Clostridium difficile has been associated with the incidence of diarrhea in hospitalized patients. ${ }^{16,17}$ In this study, there was not any relationship between diarrhea and the length of stay (LOS).

The limitation of this study was the incomplete medical record documents of hospitalized pneumonia under-five children in the Department of Child Health RSHS Bandung in the period from January-December 2012 .

This study concludes that in general, the average LOS for either with major or minor comorbidity is higher than it has been defined by the INA-DRG so that further studies need to be conducted on the clinical management aspect of under-five pneumonia patients with minor or major comorbidity in order to produce efficient services that will not cause a loss for the hospital.

In the INA-DRG, congenital heart disease itself is not included in the list of comorbidities, but it is included in the form of heart failure. This study showed that congenital heart disease was the most common comorbidity and had the highest and the most significant risk ratio and correlation with the LOS even in the absence of heart failure. Therefore, it is necessary to conduct further studies and rediscussions concerning the basis of the LOS set by the government.

\section{References}

1. Pusat Data dan Surveilans Epidemiologi (Pusdasure) Kementrian Kesehatan RI. Situasi pneumonia balita di Indonesia. Jakarta: Kementrian Kesehatan RI; 2010.

2. Departemen Kesehatan RI. Tarif Indonesia Diagnosis Related Group (INA-DRG), rumah sakit umum dan khusus. Jakarta: Departemen Kesehatan RI; 2007.

3. Nofitasari ST, Mahawati E. Analisis lama perawatan (LOS) partus seksio caesarea pada pasien jamkesmas rawat inap berdasarkan INA-CBG's di Rumah Sakit Islam Sultan Agung Semarang tahun 2010. FIKI. 2013;1(1):1-18.

4. The United Nations Children's Fund (UNICEF)/World Health Organization (WHO). Pneumonia : the forgotten killer of children. 2006.

5. Pichard C, Kyle UG, Morabia A, Perrier A, Vermeulen B, Unger P. Lean body mass depletion at hospital admission is associated with an increased length of stay. Am J Clin Nutr. 2004;79(4):613-8.

6. Keusch GT. The history of nutrition: 
malnutrition, infection and immunity. J Nutr. 2003;133(1):336S-40S.

7. Marcos A, Nova E, Montero A. Changes in the immune system are conditioned by nutrition. Eur J Clin Nutr. 2003;57(Suppl1):S66-S9.

8. Schaible UE, Kaufmann SHE. Malnutrition and infection: complex mechanisms and global impacts. PLoS Med. 2007;4(5):e115.

9. Cunningham-Rundles S, McNeeley DF, Moon A. Mechanisms of nutrient modulation of the immune response. J Allergy Clin Immunol. 2005;115(6):111928.

10. Sadoh W, Osarogiagbon W. Underlying congenital heart disease in Nigerian children with pneumonia. Afr Health Sci. 2013;13(3):607-12.

11. Sadoh W. Natural history of ventricular septal defect in Nigerian children. South Afr J Child Hlth. 2010;4:16-9.

12. Healy F, Hanna B, Zinman R. Pulmonary complications of congenital heart disease. Paediatr Respir Rev. 2011;13(1):10-5.
13. Moschovis PP, BanajehS, MacLeodWB, Saha S, Hayden D, Christiani DC, et al. Childhood anemia at high altitude : risk factors for poor outcomes in severe pneumonia. Pediatrics. 2013;132 (5):e1156-62

14. Krigger KW. Cerebral palsy : an overview. Am Fam Phys. 2006;73(1):91-100.

15. Walker CL, Perin J, Katz J, Tielsch JM, Black RE. Diarrhea as a risk factor for acute lower respiratory tract infections among young children in low income settings. J Glob Health. 2013;3(1):010402.

16. Dial S, Alrasadi K, Manoukian C, Huang A, Menzies D. Risk of Clostridium difficile diarrhea among hospital inpatients prescribed proton pump inhibitors: cohort and case-control studies. CMAJ. 2004;171(1):33-8.

17. Sandokji AM, Murshid KR, El-Badry AA, AlAli KH, Shalaby SA. Infectious nosocomial diarrhea in the surgical wards: role of parasites and microbes imply stool analysis. J Taibah Univ Sci. 2009;4(1):7381. 